\title{
Evaluation of Factors which Influence Mortality in Gram-positive Bacteremia in Hemodialysis Patients
}

\author{
Kerry Anne Rambaran ${ }^{1}$, Saeed K. Alzghari ${ }^{2}$, Charles F. Seifert ${ }^{3}$
}

1. Clinical Sciences, Keck Graduate Institute, Claremont, USA 2. Genomics, Gulfstream Diagnostics, Dallas, USA 3. Pharmacy Practice, Texas Tech University Health Sciences Center School of Pharmacy, Lubbock, USA

$\square$ Corresponding author: Kerry Anne Rambaran, kerry.rp@gmail.com

Disclosures can be found in Additional Information at the end of the article

\section{Abstract}

Vascular access infection is one of the major contributors to hemodialysis (HD) patient morbidity and mortality. There is a paucity of consensus guidelines on vancomycin use in the HD population. The primary objective of this study was to determine if vancomycin serum concentrations were associated with positive outcomes in HD patients with Gram-positive bacteremia. A retrospective cohort study conducted at a 443-bed tertiary teaching county hospital from January 1, 2010 to January 1, 2016 was performed. Patients aged 18-89, with chronic renal failure on hemodialysis who presented with positive blood cultures with Grampositive bacteria and received intravenous vancomycin for at least 24 hours were evaluated. A multivariate analysis was utilized comparing factors related to outcomes including Simplified Acute Physiology Score II (SAPS II), loading dose, 30-day mortality and vancomycin serum concentrations. A total of 139 patients were obtained, 90 of whom had documented pre-dialysis serum vancomycin concentrations. A multivariate analysis showed that a lower SAPS II score [OR 1.220 (95\% CI: 1.086-1.370, p < 0.0001)], a higher loading dose/kg [OR 0.7911 (0.6302$0.9929, \mathrm{p}=0.0239)]$, and pre-dialysis concentrations between 15 and $20 \mathrm{mcg} / \mathrm{mL}$ [0.05437 (95\% CI: 0.0033-0.8891, $\mathrm{p}=0.0099$ )] were associated with decreased mortality (overall multivariate model, $\mathrm{p}<0.0001$ ). When patient acuity and loading dosing are taken into account, pre-dialysis vancomycin serum concentrations between 15 and $20 \mathrm{mcg} / \mathrm{mL}$ were associated with decreased mortality in Gram-positive bacteremic intermittent HD patients. Further prospective studies are needed to assess whether targeting a pre-dialysis serum vancomycin concentration of 15$20 \mathrm{mcg} / \mathrm{mL}$ can improve mortality.

Received 06/19/2018

Review began 06/19/2018 Review ended 06/28/2018 Published 07/03/2018

\section{(C) Copyright 2018}

Rambaran et al. This is an open access article distributed under the terms of the Creative Commons Attribution License CC-BY 3.0., which permits unrestricted use, distribution, and reproduction in any medium, provided the original author and source are credited.
Categories: Internal Medicine, Nephrology, Infectious Disease Keywords: hemodialysis, vancomycin, vascular access, pre-dialysis

\section{Introduction}

According to the United States Renal Data System (USRDS) 2016 annual report, $87.9 \%$ of incident end-stage renal disease (ESRD) patients initiated renal replacement therapy with hemodialysis (HD). While the rate of hospitalization in HD patients due to infection has decreased to $10.6 \%$ over the years, it remains a significant issue in this patient [1]. Infection, often related to vascular access, is one of the major contributors to HD patient morbidity and mortality, accounting for 9.5 to $36 \%$ of deaths [2-3]. Vascular access infections (most commonly found in patients utilizing dialysis catheters) are reported to be the source in up to 48 to $73 \%$ of all bacteremias in HD patients [4]. As such, antibiotic use in HD patients is not uncommon, particularly vancomycin, as it provides coverage against Gram-positive organisms inclusive of 
Staphylococcus and Streptococcus [5-6]; Staphylococcus aureus is reported as one of the leading causes of bacteremia, with a 1-year all-cause mortality of $62 \%$ and 5-year mortality of $72 \%$ [7].

Vancomycin is a glycopeptide antibiotic which has an elimination half-life of 5-11 hours in adults with normal renal function and 200-250 hours in patients with ESRD [8-10]. In nonESRD patients, typical doses are calculated based on $15 \mathrm{mg} / \mathrm{kg}$ every 8 to 12 hours with a treatment target trough serum concentration of at least $10 \mathrm{mcg} / \mathrm{mL}$ or 15 to $20 \mathrm{mcg} / \mathrm{mL}$ in severe infections [11]. It is suggested that in order for HD patients to obtain a 'trough' serum concentration between 15 and $20 \mathrm{mcg} / \mathrm{mL}$, a loading dose of approximately $20 \mathrm{mg} / \mathrm{kg}$ dosed may be required; however, there is no data to confirm these levels are substitute markers of the desired area under the curve (AUC) [12]. It should be noted that vancomycin is partially removed (approximately 30\%-50\%) by most of the currently available high flux HD filters [1316].

Of note, Vandecasteele et al. reported an established linear relationship between AUC/MIC (minimum inhibitory concentration) and pre-hemodialysis vancomycin serum concentrations. They purported that for bacteria with an MIC of $1 \mathrm{mcg} / \mathrm{L}$, pre-hemodialysis vancomycin serum concentrations of 10, 15 and $20 \mathrm{mcg} / \mathrm{mL}$ corresponded to the calculated 24 hour AUC/MIC of 269, 404 and 538 respectively in patients being dialyzed with high flux dialyzers. Thus leading to the conclusion that a pre-dialysis serum concentration of $15-20 \mathrm{mcg} / \mathrm{mL}$ or greater may be adequate to treat oxacillin-resistant Staphylococcus aureus (ORSA) infections with a vancomycin MIC of $1-2 \mathrm{mcg} / \mathrm{mL}$ [17-18]. Moreover, an AUC/MIC $\geqslant 400$ has been shown to correlate best with clinical success. As such, recommendations for therapeutic drug monitoring of vancomycin has been published by the American Society of Health-System Pharmacists (ASHP), Infectious Disease Society of America (IDSA), and Society of Infectious Disease Pharmacists (SIDP) [19-22]. However, guidelines specific to the HD patient population are lacking and thus most healthcare facilities and systems have traditionally resorted to adapting the general guidelines to HD patients. Adaptation of these guidelines addresses, in some regard, the renal clearance but does not account for the non-renal clearance of vancomycin. As such, adapted vancomycin dosing protocols usually involve administering a dose after or during the last hour of dialysis. Given the lack of a standardized guideline for this patient population, therapeutic monitoring is of great importance to ensure appropriate doses are administered in order to acquire therapeutic serum concentrations [9]. Thus, while there is a plethora of literature to suggest dosing regimens in adults with normal renal function, there is still a degree of uncertainty as to what the proper dosing regimen would be in this hemodialysis patient population. The goal of this study is to determine if a pre-dialysis vancomycin serum concentration of $15-20 \mathrm{mcg} / \mathrm{mL}$ is associated with positive outcomes in patients undergoing intermittent hemodialysis (IHD) with Gram-positive bacteremia.

\section{Materials And Methods}

This retrospective cohort study was conducted at a 443-bed tertiary teaching county hospital from January 1, 2010 to January 1, 2016. The year 2010 was selected as the start of the data collection since this was one-year post-implementation of online documentation thus allowing for an adjustment time period. Patients were identified using the International Classification of Diseases, Ninth Revision, Clinical Modification (ICD-9 CM) code for bacteremia (R790.7) and/or the International Classification of Diseases, Tenth Revision, Clinical Modification (ICD-10 CM) code (R78.81). According to the criteria of Tabachnick and Fidell $(n \geqslant 50+8 m$, where $m$ is the number of independent variables in the model $[\mathrm{m}=2]$ ), the sample size of 139 patients was sufficient to avoid a type II error [23-24]. Inclusion criteria consisted of patients aged 18-89, with chronic renal failure (stage 5 chronic kidney disease) on intermittent hemodialysis who presented with positive blood cultures with Gram-positive bacteria, received vancomycin for at least 24 hours, and were admitted to the intensive care unit (ICU). All patients were treated with high flux polysulfone Optiflux F160NR dialyzers (1.5 m2) (Fresenius Medical Care North 
America). Exclusion criteria consisted of patients who had an allergic reaction or hypersensitivity to vancomycin, were pregnant, received peritoneal dialysis, had only a onetime hemodialysis session for toxicity, received only one dose of vancomycin, were on continuous renal replacement therapy or sustained low-efficiency dialysis, or had nonvancomycin susceptible bacteria (Figure 1). Age, sex, dry weight, the first pre-dialysis vancomycin serum concentration, organism(s), loading dose, length of dialysis session, mortality, and length of stay were collected. The wet weight (weight upon admission) was utilized for vancomycin dosing. Simplified Acute Physiology Score II (SAPS II) scores were calculated upon admission to the ICU, post the vancomycin loading dose, and utilized as the predictor of mortality. This study was approved by the appropriate institutional review board.

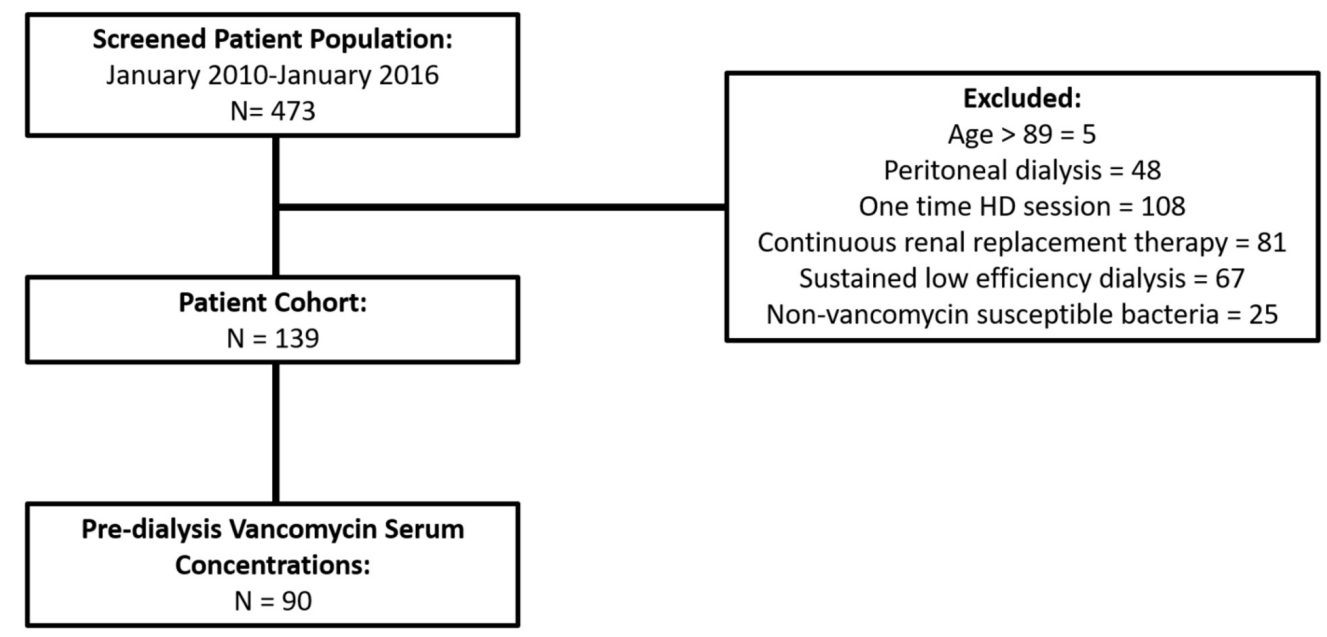

FIGURE 1: Flowchart of patient selection.

Bacteremia was defined as the occurrence of two consecutive positive blood cultures in the same set drawn on the same day and therapy was adjusted accordingly once susceptibility results were obtained [25]. Clinical cure was defined as a complete resolution of clinical signs and symptoms of infection (fever, leukocytosis, local signs of infection, and negative blood cultures) and mortality was defined as 30-day mortality. Pre-dialysis levels were drawn prior to the IHD session following the loading dose. The vancomycin loading dose was determined by the physician. For levels less than $15 \mathrm{mcg} / \mathrm{mL}$ post HD, 500-1000 $\mathrm{mg}$ was given.

Statistical analyses were performed using Analyse-it ${ }^{\circledR}$ for Microsoft Excel 3.90 .7 (Copyright 1997-2016, Leeds, England). Descriptive statistics were used to compare patient demographics. Nominal data were compared using Pearson's chi-squared or Fisher's exact test. Continuous data were analyzed using the Shapiro-Wilk test for normality. In the case of non-parametric data, the median was used for central tendency with interquartile range (IQR) for the dispersion. The Mann-Whitney U test and Spearman's correlation were used as appropriate. A multivariate analysis was utilized comparing factors related to outcomes including SAPS II score, vancomycin dose, and in-hospital mortality. Factors that had a p-value $<0.02$ were kept in the model and the multivariate analysis was repeated. This was executed for each outcome variable. An alpha level of significance was defined a priori as $<0.05$.

\section{Results}

The studied patient cohort consisted of 139 ESRD patients receiving IHD (76 male, 63 female; median (IQR) age of 58 years (IQR 21.1)). Median weight was $77.1 \mathrm{~kg}$ (IQR $30.7 \mathrm{~kg}$ ). The 


\section{Cureus}

majority of patients presented with infections of ORSA (MIC $<2 \mathrm{mg} / \mathrm{mL}$ ), Staphylococcus epidermidis, coagulase-negative staphylococci, and/or oxacillin sensitive Staphylococcus aureus (OSSA) (Figure 2). The average duration of dialysis was $3.7 \mathrm{~h}$ (standard deviation (SD) $0.8 \mathrm{~h}$, range 1.0-6.0 h), average dialysate flow rate was $720 \mathrm{~mL} / \mathrm{min}$ (SD $31.3 \mathrm{~mL} / \mathrm{min}$, range 600-800 $\mathrm{mL} / \mathrm{min}$ ), and the average blood flow rate was $386 \mathrm{~mL} / \mathrm{min}$ (SD $40.0 \mathrm{~mL} / \mathrm{min}$, range 270-450 $\mathrm{mL} / \mathrm{min}$ ). Of 139 patients, 90 had documented pre-dialysis serum vancomycin concentrations. The median (IQR) pre-hemodialysis serum concentration of vancomycin was $16.3 \mathrm{mcg} / \mathrm{mL}$ (9.28) (Table 1). Of the 90 patients, 28 had pre-dialysis concentrations less than $15 \mathrm{mcg} / \mathrm{mL}$ and 27 had pre-dialysis concentrations more than $20 \mathrm{mcg} / \mathrm{mL}$ and 26 patients had a pre-dialysis concentration between 15 and $20 \mathrm{mcg} / \mathrm{mL}$.

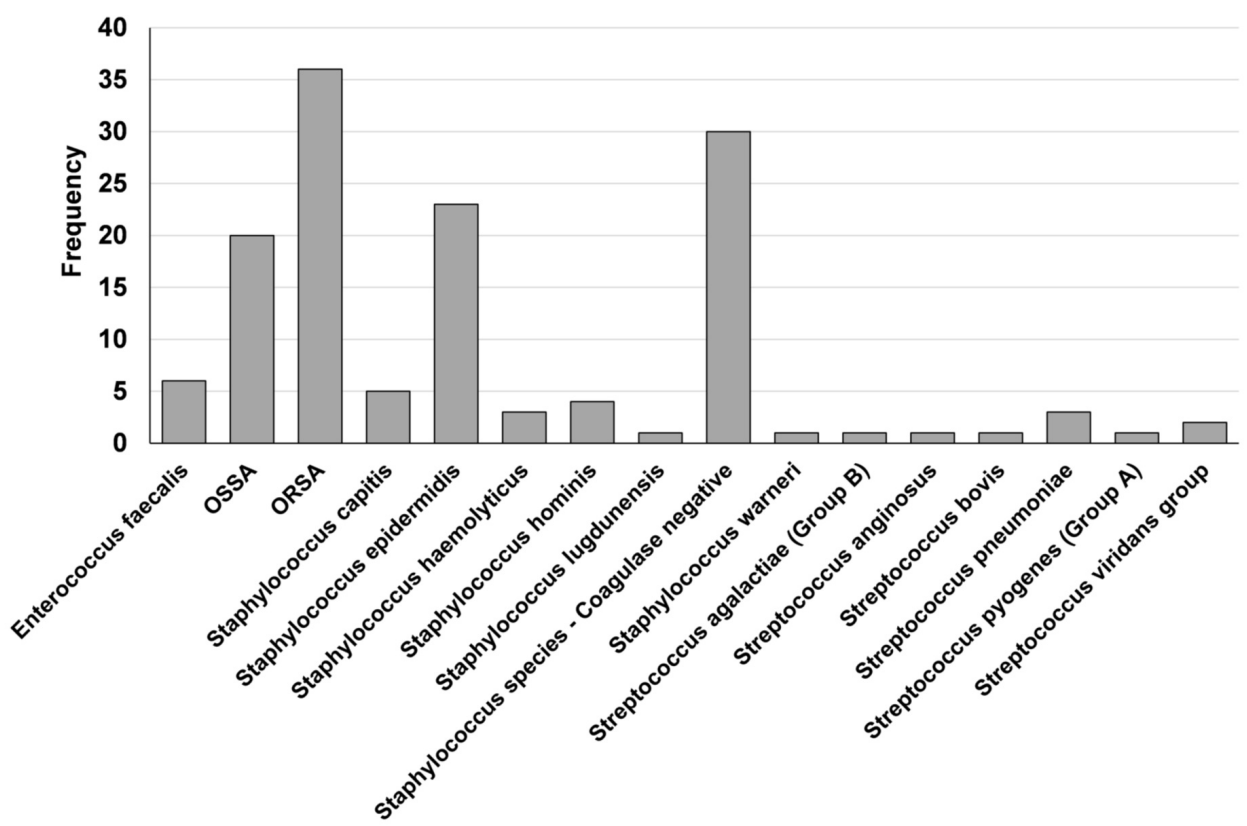

FIGURE 2: Frequency of blood culture organisms $(\mathrm{N}=90)$.

ORSA: Oxacillin-resistant Staphylococcus aureus; OSSA: Oxacillin-sensitive Staphylococcus aureus. 


\section{Cureus}

\section{Characteristics}

Median (IQR) age

$\operatorname{Sex}(M / F)$

Median (IQR) weight in $\mathrm{kg}$

Median (IQR) SAPS-II score

Mean \pm SD dialysate flow rate

Mean $\pm \mathrm{SD}$ duration of $\mathrm{HD}$

Mean \pm SD blood flow rate

Median (IQR) pre-HD vancomycin serum concentration

\section{Patient Sample}

$58(21.1)$

$47 / 43$

$77.1(30.7)$

$35(14.0)$

$720 \mathrm{~mL} / \mathrm{min} \pm 31.3$

$3.7 \mathrm{hr} \pm 0.8$

$386 \mathrm{~mL} / \mathrm{min} \pm 40$

$16.3 \mathrm{mcg} / \mathrm{mL}(9.28)$

\section{TABLE 1: Population baseline characteristics $(N=90)$.}

HD: Hemodialysis; IQR: Interquartile range; SAPS-II: Simplified Acute Physiology Score II; SD: Standard deviation.

For the entire sample size of 139 patients, the median SAPS II score was 35 (IQR 15.0). For the 26 patients achieving the pre-dialysis serum concentration of $15-20 \mathrm{mcg} / \mathrm{mL}$, the median SAPS II score was 34.5 (IQR 12.3) compared to 35.5 (IQR 14.0) in those that did not achieve that serum concentration ( $\mathrm{p}=0.9$ ). The median (IQR) SAPS II scores were significantly higher in patients who died [47 (8.2)] than those patients who survived [34 (12.2)] $(\mathrm{p}<0.0001)$. Median (IQR) loading doses of vancomycin were lower in patients who died [11.60 mg/kg (3.51)] versus those who survived $[13.79 \mathrm{mg} / \mathrm{kg}(5.51)](\mathrm{p}=0.09)$ but did not reach significance on its own. In hospital, mortality was lower in patients who achieved pre-dialysis serum vancomycin concentrations between 15 and $20 \mathrm{mcg} / \mathrm{mL}(1 / 26$, 3.8\%) versus those who did not achieve a predialysis serum concentration between 15 and $20 \mathrm{mcg} / \mathrm{mL}(11 / 64,17.2 \%)$ but did not reach significance $(\mathrm{p}=0.09)$ on its own (Tables 2, 3). A multivariate analysis showed that SAPS II score [OR 1.220 (95\% CI: 1.086-1.370, p < 0.0001)], loading dose/kg [OR 0.7911 (95\% CI: $0.6302-0.9929, \mathrm{p}=0.02)$ ], and pre-dialysis serum vancomycin concentrations between 15 and $20 \mathrm{mcg} / \mathrm{mL}$ [0.05437 (95\% CI: 0.0033-0.8891, p =0.01)] were associated with decreased mortality (overall multivariate model, $\mathrm{p}<0.0001$ ) (Table 4). Patients who achieved a clinical cure had a significantly higher median (IQR) pre-dialysis vancomycin serum concentration of $18.90 \mathrm{mcg} / \mathrm{mL}(19.28)$ than those patients who did not achieve a clinical cure $16.20 \mathrm{mcg} / \mathrm{mL}$

(9.57) $(\mathrm{p}=0.04)$. 


\section{Cureus}

\begin{tabular}{|c|c|c|c|}
\hline Parameter & Alive Patients & Deceased Patients & p-Value \\
\hline Median (IQR) SAPS II & $34(12.2)$ & $47(8.2)$ & 0.0001 \\
\hline Median (IQR) loading vancomycin dose & $13.79 \mathrm{mg} / \mathrm{kg}(5.51)$ & $11.6 \mathrm{mg} / \mathrm{kg}(3.51)$ & 0.09 \\
\hline
\end{tabular}

\section{TABLE 2: Univariate analysis of mortality $(\mathrm{N}=90)$.}

IQR: Interquartile range; SAPS II: Simplified Acute Physiology Score II.

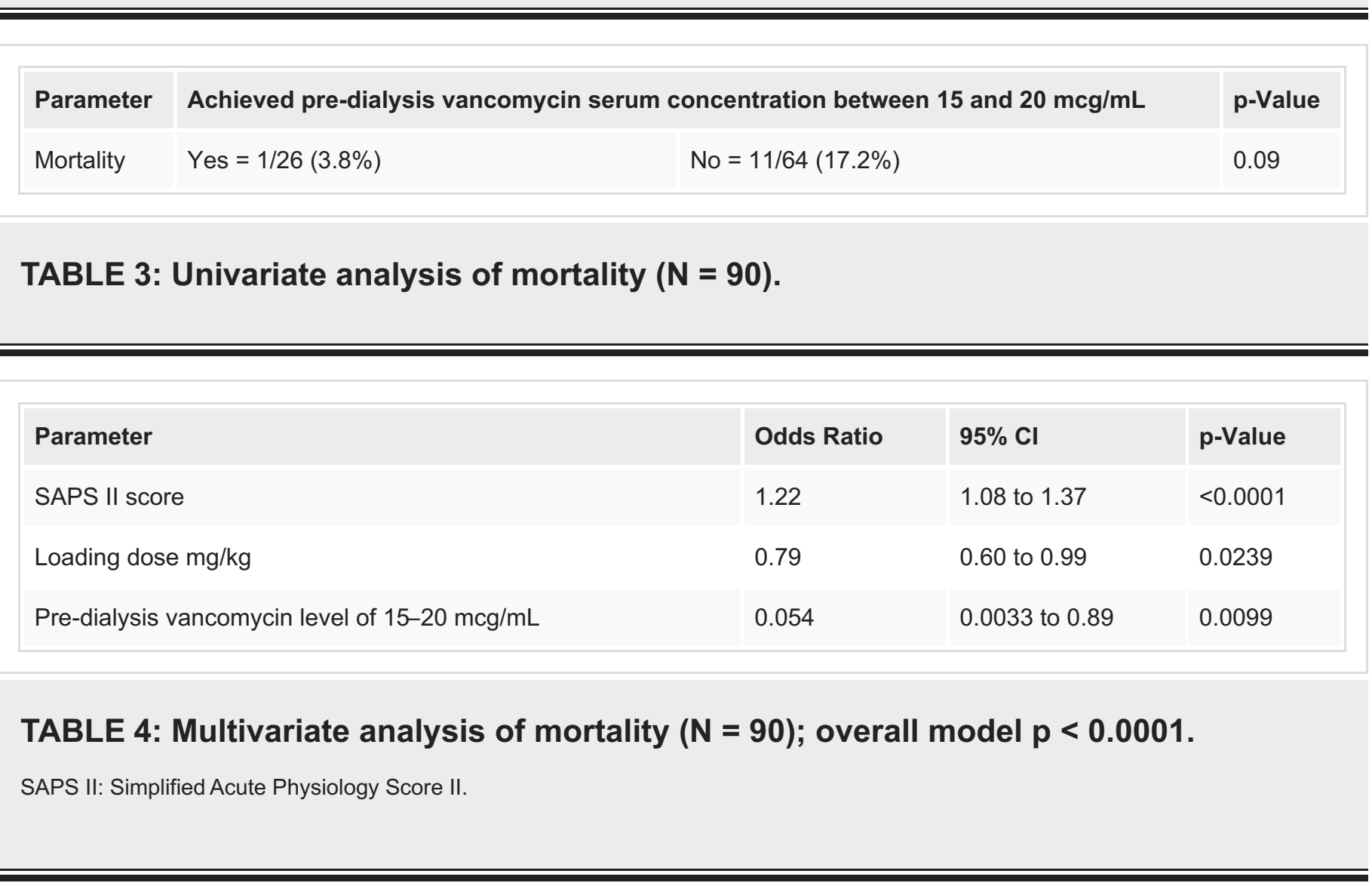

\section{Discussion}

The findings presented here demonstrated a significant association between a pre-dialysis serum concentration of $15-20 \mathrm{mcg} / \mathrm{mL}$ and reduced mortality in patients receiving intermittent hemodialysis. The study did not show any statistically significant differences in mortality or relapse/recurrence rates with various post-dialysis vancomycin serum concentrations. Based on the multivariate analysis, both loading dose and pre-dialysis serum vancomycin concentrations had a larger impact on mortality in patients with higher acuity.

Unlike patients with normal renal function, hemodialysis patients have multiple factors that need to be considered, such as dialysis modality and type, timing of vancomycin administration, target serum concentrations, and pharmacokinetic factors. Studies have suggested using loading doses of 15-20 mg/kg followed by maintenance doses of 500-1500 mg $[6,26]$. In a three-way randomized crossover trial conducted by Mason et al., a loading dose of 15 $\mathrm{mg} / \mathrm{kg}$ resulted in a pre-hemodialysis vancomycin serum concentration of $23.8 \mathrm{mcg} / \mathrm{mL} \pm 4.8$ two days later [27]. Conversely, Barth and DeVincenzo reported the pre-hemodialysis 
vancomycin serum concentrations two days after a loading dose of $15 \mathrm{mg} / \mathrm{kg}$ and $20 \mathrm{mg} / \mathrm{kg}$ were $12.6 \mathrm{mcg} / \mathrm{mL}$ and $16.3 \mathrm{mcg} / \mathrm{mL}$, respectively [6]. It should be noted that this patient population has multiple factors that can affect the achievement of 'trough' levels of $20 \mathrm{mcg} / \mathrm{mL}$. Thus whilst some studies may be able to achieve this level with a loading dose of $12-20 \mathrm{mg} / \mathrm{kg}$, it may not be possible in other studies as the patient specific dynamic affects the results. Hence using a one size fits all dosing regimen may potentiate the risk for underdosing or overdosing these patients. One could argue that higher loading doses can potentiate toxicity; however, nephrotoxicity in this patient population is negligible as approximately $30-50 \%$ of vancomycin is removed in one dialysis session [13-16]. Literature has shown there is a rebound in plasma vancomycin concentrations approximately 3-6 hours after high flux dialysis, thus drawing a trough level immediately after dialysis would lead to a gross over-estimation in dialytic clearance [28]. One way to circumvent this overestimation would be to look at pre-HD levels. Several studies have shown dosing based on pre-HD levels achieves therapeutic concentrations, though the endpoint of mortality has not been fully explored [29-30]. Theoretically, if the preHD levels are therapeutic, then it could be postulated there may be an improvement in mortality. Additionally, the current literature recommends using weight-based doses (loading and maintenance) in patients receiving vancomycin; however, there is no consensus guideline as to which weight (i.e., wet or dry, actual or ideal) should be used for dosing in hemodialysis patients. Moreover, the protocol at the time of this review placed emphasis on administering a maintenance dose four hours post dialysis. Additionally, whilst the protocol was not specific to pre-dialysis level drawing, the levels obtained were drawn three hours before the next dialysis session. Since there is no consensus guideline on when to draw levels and administer the dose, our protocol does not significantly impact our findings. In our patient population, the wet weight was used for dosing purposes and may be a point of contention. Interestingly, lower predialysis serum concentrations were more prevalent in patients who were $\geqslant 61$ years. This study was not designed to look at the relationship between dosing, serum concentrations and age; however, this should be explored further in this population.

The results obtained in this study may be generalizable to the hemodialysis population; however, this study has several limitations. There was no specification as to when the loading dose was given before the first dialysis session or at the end of the first dialysis session. Secondly, the patients included were already established on hemodialysis without consideration for any residual renal function. Finally, patients may have received a dose of vancomycin prior to presenting to our institution. As such, these doses were not accounted for, nor were they present in the documentation. Of note, two consecutive positive blood cultures were obtained, which theoretically may be unnecessary for organisms like Staphylococcus aureus given the risk involved in this patient population. However, given this patient population is predisposed to infections, treatment was initiated until the second culture result was available.

\section{Conclusions}

When patient acuity and loading dosing are taken into account, pre-dialysis vancomycin serum concentrations between 15 and $20 \mathrm{mcg} / \mathrm{mL}$ were associated with a decrease in mortality in Gram-positive bacteremic IHD patients. Further prospective studies are needed to assess whether these targeted serum vancomycin concentrations improve mortality.

\section{Additional Information}

\section{Disclosures}

Human subjects: Consent was obtained by all participants in this study. TTUHSC Lubbock/Odessa Institutional Review Board issued approval L16-049. The IRB acknowledges that this research meets the criteria for exemption from formal IRB review in accordance with 45 CFR 46.101(4). All data are in existence at the time of the request for exemption and no identifying information will be recorded. A request to waive individual HIPAA authorization has 
been submitted and is granted in accordance with 45 CFR 164.512(i)(2)(ii). This application was screened for exempt status according to TTUHSC policies and the provisions of applicable federal regulations. The study was found not to require formal IRB review because the research falls into one of the categories specifically designated as exempt per 45 CFR 46.101. Animal subjects: All authors have confirmed that this study did not involve animal subjects or tissue. Conflicts of interest: In compliance with the ICMJE uniform disclosure form, all authors declare the following: Payment/services info: All authors have declared that no financial support was received from any organization for the submitted work. Financial relationships: All authors have declared that they have no financial relationships at present or within the previous three years with any organizations that might have an interest in the submitted work. Other relationships: All authors have declared that there are no other relationships or activities that could appear to have influenced the submitted work.

\section{Acknowledgements}

This work was presented at the Annual Meeting of the American College of Clinical Pharmacy in Hollywood, FL on October 23, 2016.

\section{References}

1. 2016 ADR chapters. (2016). Accessed: June 15, 2018: https://www.usrds.org/2016/view/Default.aspx.

2. Dhingra RK, Young EW, Hulbert-Shearon TE, Leavey SF, Port FK: Type of vascular access and mortality in U.S. hemodialysis patients. Kidney Int. 2001, 60:1443-1451. 10.1046/j.15231755.2001.00947.x

3. Zhang JC, Al-Jaishi AA, Na Y, de Sa E, Moist LM: Association between vascular access type and patient mortality among elderly patients on hemodialysis in Canada. Hemodial Int. 2014, 18:616-624. 10.1111/hdi.12151

4. Nassar GM, Ayus JC: Infectious complications of the hemodialysis access . Kidney Int. 2001, 60:1-13. 10.1046/j.1523-1755.2001.00765.x

5. Barcenas CG, Fuller TJ, Elms J, Cohen R, White MG: Staphylococcal sepsis in patients on chronic hemodialysis regimens: intravenous treatment with vancomycin given once weekly. Arch Intern Med. 1976, 136:1131-1134. 10.1001/archinte.1976.03630100043012

6. Barth RH, DeVincenzo N: Use of vancomycin in high-flux hemodialysis: experience with 130 courses of therapy. Kidney Int. 1996, 50:929-936.

7. Yahav D, Yassin S, Shaked H, Goldberg E, Bishara J, Paul M, Leibovici L: Risk factors for longterm mortality of Staphylococcus aureus bacteremia. Eur J Clin Microbiol Infect Dis. 2016, 35:785-790. 10.1007/s10096-016-2598-8

8. Pollard TA, Lampasona V, Akkerman S, Tom K, Hooks MA, Mullins RE, Maroni BJ: Vancomycin redistribution: dosing recommendations following high-flux hemodialysis . Kidney Int. 1994, 45:232-237.

9. Zelenitsky SA, Ariano RE, McCrae ML, Vercaigne LM: Initial vancomycin dosing protocol to achieve therapeutic serum concentrations in patients undergoing hemodialysis. Clin Infect Dis. 2012, 55:527-533. 10.1093/cid/cis458

10. Rodvold KA, Blum RA, Fischer JH, Zokufa HZ, Rotschafer JC, Crossley KB, Riff LJ: Vancomycin pharmacokinetics in patients with various degrees of renal function. Antimicrob Agents Chemother. 1988, 32:848-852. 10.1128/AAC.32.6.848

11. Rybak MJ, Lomaestro BM, Rotschafer JC, et al.: Therapeutic monitoring of vancomycin in adults: summary of consensus recommendations from the American Society of Health-System Pharmacists, the Infectious Diseases Society of America, and the Society of Infectious Diseases Pharmacists. Pharmacotherapy. 2009, 29:1275-1279. 10.1592/phco.29.11.1275

12. Álvarez R, López Cortés LE, Molina J, Cisneros JM, Pachón J: Optimizing the clinical use of vancomycin. Antimicrob Agents Chemother. 2016, 60:2601-2609. 10.1128/AAC.03147-14

13. Lin SY, Shen MC, Hwang SJ, Chen YH, Chen TC, Chiu YW, Lu PL: Evaluation of vancomycin dosing protocols to achieve therapeutic serum concentrations in patients receiving high-flux haemodialysis. Int J Antimicrob Agents. 2014, 43:384-385. 10.1016/j.ijantimicag.2014.01.002

14. Keller F, Hörstensmeyer C, Looby M, Borner K, Pommer W, Erdmann K, Giehl M: Vancomycin 
dosing in haemodialysis patients and Bayesian estimate of individual pharmacokinetic parameters. Int J Artif Organs. 1994, 17:19-26. 10.1177/039139889401700104

15. Böhler J, Reetze-Bonorden P, Keller E, Kramer A, Schollmeyer PJ: Rebound of plasma vancomycin levels after haemodialysis with highly permeable membranes. Eur J Clin Pharmacol. 1992, 42:635-639. 10.1007/BF00265928

16. Lanese DM, Alfrey PS, Molitoris BA: Markedly increased clearance of vancomycin during hemodialysis using polysulfone dialyzers. Kidney Int. 1989, 35:1409-1412.

17. Vandecasteele SI, De Bacquer D, De Vriese AS: Implementation of a dose calculator for vancomycin to achieve target trough levels of $15-20 \mu \mathrm{g} / \mathrm{mL}$ in persons undergoing hemodialysis. Clin Infect Dis. 2011, 53:124-129. 10.1093/cid/cir337

18. El Nekidy WS, El-Masri MM, Umstead GS, Dehoorne-Smith M: Factors influencing vancomycin loading dose for hospitalized hemodialysis patients: prospective observational cohort study. Can J Hosp Pharm. 2012, 65:436-442. 10.4212/cjhp.v65i6.1191

19. Rybak M, Lomaestro B, Rotschafer JC, et al.: Therapeutic monitoring of vancomycin in adult patients: a consensus review of the American Society of Health-System Pharmacists, the Infectious Diseases Society of America, and the Society of Infectious Diseases Pharmacists. Am J Health Syst Pharm. 2009, 66:82-98. 10.2146/ajhp080434

20. Fitzgibbons LN, Puls DL, Mackay K, Forrest GN: Management of gram-positive coccal bacteremia and hemodialysis. Am J Kidney Dis. 2011, 57:624-640. 10.1053/j.ajkd.2010.12.013

21. Liu C, Bayer A, Cosgrove SE, et al.: Clinical practice guidelines by the Infectious Diseases Society of America for the treatment of methicillin-resistant Staphylococcus aureus infections in adults and children. Clin Infect Dis. 2011, 52:e18-e55. 10.1093/cid/ciq146

22. Vandecasteele SJ, De Vriese AS: Vancomycin dosing in patients on intermittent hemodialysis . Semin Dial. 2011, 24:50-55. 10.1111/j.1525-139X.2010.00803.x

23. Tabachnick BG, Fidell LS: Using Multivariate Statistics, 6th Edition. Pearson, Boston; 2013.

24. Wingard RL, Chan KE, Lazarus JM, Hakim RM: The "right" of passage: surviving the first year of dialysis. Clin J Am Soc Nephrol. 2009, 4:S114-S120. 10.2215/CJN.04360709

25. Hall KK, Lyman JA: Updated review of blood culture contamination . Clin Microbiol Rev. 2006, 19:788-802. 10.1128/CMR.00062-05

26. Brown M, Polisetty R, Gracely EJ, Cuhaci B, Schlecht HP: Weight-based loading of vancomycin in patients on hemodialysis. Clin Infect Dis. 2011, 53:164-166. 10.1093/cid/cir322

27. Mason NA, Neudeck BL, Welage LS, Patel JA, Swartz RD: Comparison of 3 vancomycin dosage regimens during hemodialysis with cellulose triacetate dialyzers: post-dialysis versus intradialytic administration. Clin Nephrol. 2003, 60:96-104.

28. Launay-Vacher V, Izzedine H, Mercadal L, Deray G: Clinical review: use of vancomycin in haemodialysis patients. Crit Care. 2002, 6:313-316. 10.1186/cc1516

29. Gunning H, Taylor G, Smyth A, et al.: An approach to optimise therapeutic vancomycin dosage in a haemodialysis population. Ir Med J. 2016, 109:465.

30. Mahmoud LB, Chaabouni Y, Ghozzi H, et al.: Optimization of therapeutic drug monitoring of vancomycin in patients with chronic hemodialysis. Clin Nephrol. 2017, 88:198-204.

10.5414/CN109091 